\title{
Olavo Bilac - Educador
}

\section{Renato Travassos}

Altíssimo poeta, notável orador e brilhante jornalista, Olavo Bilac foi também excelente educador. Pode-se mesmo dizer que êle tinha o gôsto inato das coisas educativas, pois estava sempre disposto a transmitir o que sabia, na esperança de que os brasileiros se apresentassem ao mundo como povo civilizado, no mesmo nível dos demais povos líderes da Humanidade. Além dos livros escolares da sua exclusiva autoria e dos que compôs em colaboração com Coelho Neto e Manoel Bonfim, Bilac jamais deixou de ser na tribuna e na imprensa um ótimo transmissor de conhecimentos, fazendo-o obediente à stua vocação irresistivel e gratuita. Há meses, na Associação Brasileira de Imprensa, tendo por tema o jornalista que, durante vinte e cinco anos, êle, sem prejuizo de suas demais atividades intelectuais, havia sido, salientado: "grato ser-me-ia falar, aproveitando o ensejo, de um Olavo Bilac educador, visto as sementes de cultura, energia e civismo lançadas por êle ao solo virgem não se terem perdido; ao contrário, germinaram em promessas de fartas e magníficas searas». "Graças à sua pregação patriótica, ruiram, desde logo, todos os preceitos contra o militarismo em o nosso país, mesmo em ambiente como o de Minas Gerais, cujo povo era até então ferrenhamente civilista, avêsso a fardas e quartéis. Seus livros escolares pròpriamente ditos, tanto em prosa quanto em verso são ainda hoje dos melhores que possuimos."

Eis-me, decorridos alguns meses, a falar de novo sôbre Olavo Bilac. Desta feita, porém, sôbre o educador, tema que, em se tratando de quem se trata, é para se desenvolver em uma alentada monografia, tarefa reservada a quem melhor se encontre apercebido dela. Como o fiz, ao falar do jornalista, faço agora, visando apenas a uma palestra, na qual o educador se relembre à pressa e, conseqüentemente de maneira informe.

No livro, na tribuna e na imprensa Bilac exerceu, em tôda a sua vida, que aliás não foi longa, efetivo magistério. Paraninfando, em 1909, a turma que se bacharelava em letras pelo Ginásio Granbery, de Juiz de Fora, pronunciou êle notável discurso, no qual se revelou em dia com os assuntos educativos mais evolvidos. Lisongeado com escolher-se para assistir, naquele ensejo, aos que, terminando o curso secundário, se despediam do conceituado educandário, rival do velho Caraça de tantas e tão nobres tradições, Bilac acentutou: "Nenhuma outra missão poderia ser mais agradável ao meu espírito, que trago há bastantes anos preocupado com os problemas do ensino. E o meu contentamento é aumentado pela simpatia especial que me inspira o Ginásio Granbery, onde se aplicam com escrúpulo rigoroso as normas da 
educação moderna, segundo o critério adotado nos Estados Unidos da América, - normas que se podem resumir dêste modo: no curso primário, a formação do espirito da criança, sem prejuizo da sua individualidade; no curso secundário, a formação do espírito de Homem, dando-lhe equilibradamente a cultura das aptidões imaginativas e o conhecimento da vida prática, e. inspirando-lhe sobretudo a confiança em si mesmo, base e ponto de partida de tôda a iniciativa individual."

Olavo Bilac preocupava-se sèriamente com os problemas educativos e seus trabalhos a respeito bem o atestam. Foi êle ainda, durante vários anos, inspetor de ensino e diretor de colégio no Distrito Federal e, particularidade que vale por um teste vocacional, era essa a única qualidade pessoal de que êle fazia praça, mencionando-a inclusive em seus cartões de visita. Sendo, pois, educador inato, estava êle sempre desperto e atuante, no quanto se relacionasse com a educação. Prescindiu de filhos para bem amar e compreender a infancia: sabia o que melhor lhe convinha à formação, segundo os reclamos da vida a ser vivida, em um mundo em constante mudança. E assim baseado no que se encontrava de mais moderno e provadamente eficiente, é que transmitia bons ensinamentos. Mu tos dos seus discursos e conferências tinham finalidade essencialmente educativa, como o tinham também muitas das suas crônicas jornalisticas.

Escrevendo para as crianças, Bilac temia realizar um livro ingênuo demais, ou, o que seria pior, um livro, como tantos há por ai, falso, cheio de história: maravilhosas e belas que desenvolvem a credulidade das crianças, fazendo-as ter mêdo de coisas que näo existem. Era preciso achar assuntos simples, humanos, naturais, que fugindo à banalidade, não fôssem fatigar o célebro do pequeno leitor, exigindo dêle uma reflexão demorada e profunda." Tendo-o, afinal, conseguido, Bilac conclue: "O livro aqui está. É um livro que não há os animais que falam, nem as fadas feiticeiras que entram pelos buracos das fechaduras; há aqui descriçóes da natureza, cenas de família, hinos ao trabalho, à fé, ao dever: alusões ligeiras à história pátria, pequenos contos em que a bondade é louvada e premiada." Com isto visava Bilac à formação de uma mentalidade infantil isenta do que constitue herança perigosa de que o seu portador jamais se livra na vida. Se quantos escrevem para crianças seguissem o exemplo do autor de Poesias Infantis, não existiriam por ai tantos livros contrários à boa educação.

Apesar de grande poeta, Bilac, atendendo a sua vocação pedagógica, abandonava a fantasia para ser realista, a fim de que a infância não se contaminasse, adquirindo uma mentalidade deformada que, mais tarde, lhe fôsse prejudicial. No seu conceito, aos jovens educandos só se deviam transmitir ensinamentos baseados na realidade. Mas, o é Bilac quem diz: "O fim da educação não é preparar eruditos frios nem sábios secos, nem ideólogos impassiveis, indiferentes às lutas sociais; é preparar homens de pensamento e ação, a um tempo compassivos e enérgicos, corajosos e hábeis, capazes de empregar valiosamente em proveito da coletividade tôdas as fôrças vivas da sua alma e todo o arsenal de conhecimentos de que se apercebeu o estudo. $\mathrm{Em}_{\mathrm{m}}$ um país novo como êste, onde quase tudo ainda está por fazer, seria absurda e monstruosa a existência de cenobitas do ideal, de anacoretas da ciência, poetas e filósofos, matemáticos ou artistas, isolados no mundo 
egoista, surdos à agitação da existência do comum dos homens, insensiveis às sugestões do meio em que vivem. O Brasil não tem excessos de servidores; ao contrário, é ainda escasso o número dos que podem amá-lo e servi-lo com verdadeira utilidade. É capital para a vida prática a importância dos estudos ginasiais. Assim como foi ótima a inovação que, na escola primária, libertou o ensino da sobrecarga das sutilezas gramaticais para de preferência dar à criança noções suscintas do mecanismo geral da vida, - foi providencial, no ensino secundário, a idéia de, com algum prejuizo das chamadas humanidades, abrir mais vasto campo à educação cientifica." Êstes conceitos, emitidos há meio século, continuam atualíssimos. Já Bilac, naquela época, preconizava o uso de normas e meios educativos de acôrdo com a chamada escola ativa, normas e meios que melhor se prestam para a formação mental e moral dos educandos sem prejuizo da sua individualidade, desde o pré-escolar, dando-selhes, em correspondência com as suas aptidões vocacionais, os necessários ensinamentos para, quando adultos, bem se conduzirem, em benefício próprio e coletivo, e inspirar-lhes sobretudo confiança em si mesmos, base e ponto de partida de tôdas as iniciativas individuais.

Bilac foi sem dúvida um verdadeiro educador. $\mathrm{E}$ a prova disto tem-se no que êle nos deixou em prosa e verso, não se falando na sua vitoriosa campanha civica, concitando as novas gerações patrícias a se unirem, colocandorse a serviço do Brasil, tanto na paz quanto na guerra, porque uma pátria só se engrandece e se eterniza, quando dispõe de filhos que a amem e a sirvam com essa consciência adquirida pelo adestramento físico e pelo preparo mental, moral e profissional. Bilac sentia, como hoje sentimos, que a educação, para ser eficiente de verdade, não pode alheiar-se do espetáculo do mundo contemporâneo, e que os seus fins é ver na criança o comêço do homem que, desde o seu nascimento, se inicia como educando.

Para dizer do valor educativo de certas páginas literárias de Bilac, basta-me o seguinte: Meu filho, quando pequenino, gostava imenso de pássaros, e os possuia de várias qualidades, engaiolados. Um dia, pessoa da família leu para êle $O$ pássaro cativo. De tal maneira aquêles versos calaram no seu espírito e tanto falaram à sua sensibilidade, que, horas depois, tôdas as gaiolas se viam vazias e, desde então, meu filho jamais prendeu um pássaro. Aquela leitura, no entanto, fôra feita sem nenhuma intenção doutrinária, tendo, por isto, causado surprêsas o seu resultado. Alegrei-me com o fato, visto se ter dado ensejo a que o menino adquirisse o sentimento pelo qual se reconhece o direito à liberdade, que nem mesmo aos pássaros de bela plumagem e mavioso canto se deve negar.

Bilac realizou uma obra educativa como, antes e depois dêle, nenhuma outra foi realizada por um só homem, no Brasil. Sua cultura, sendo um prolongamento da cultura européia, reflete, a cada passo, aspectos do velho tronco racial a que pertencemos e do qual não nos podemos separar, sem que pretendamos nos estiolar, à maneira de ramo de árvore que se destaca do respectivo caule. Talvez por isto mesmo alguém o julgasse a mais bela flôr da civilização brasileira. E Bilac o era sem nenhum favor.

Tendo vivido relativamente pouco, pois morreu aos cinqüenta e três anos de idade, o grande poeta não se deixou demorado nas abstrações 
inconseqüentes. Se pagou brilhantemente o seu tributo ao sonho, nem por isto desamou a realidade. Nas suas horas de desperto, empenhou-se na ação construtiva, tendo por instrumentos de trabalho a inteligência e a cultura. Agradecidas pelo que êle fêz, visando à defesa e ao engrandecimento do Brasil, as nossas classes armadas elegeram-no símbolo patriótico. Embora a morte importuna se apressasse em fechar-lhe os olhos, a sua voz não se calou nem se calará, ouvindo-se nítida e precisa através dos tempos.

As sementes de civismo que êle lançou no solo pátrio não se perderam. Bendigamos, pois, o semeador providencial. Dêle êste legado patriótico, que se transmitirá de geração a geração. Ante à Bandeira, amado símbolo da Pátria, todo o brasileiro, jovem ou velho, há de sempre dizer de si para consigo, cheio de intusiasmo ou tranzido de comoção:

Contemplando o teu vulto sagrado,

Compreendemos o nosso dever:

E o Brasil, por seus filhos amado,

Poderoso e feliz há de ser!

Naturalmente as nossas classes armadas, cônscias do valor das fôrças abstratas da inteligência e da cultura, sentiram necessidade de as sincronizar com as suas próprias fôrças, para maior segurança e mais estímulo, na conquista do porvir, êsse amanhã glorioso pelo qual tanto ansiamos esperançados. Daí o terem se valido de Bilac que bem compreendia a situação do Brasil, e o poeta soube corresponder ao que dêle se esperava. Para levar a bom têrmo, como de fato o levou, o seu apostolado cívico, Bilac possuia em si os dois indispensáveis requisitos: a confiança e a exaltação. Ouçamô-lo: "A verdade é que tôda a fôrça efetiva e tôda a verdadeira superioridade são confiantes e exaltadas. O ceticismo é a debilidade e a esterilidade. Só o entusiasmo é forte e criador. A Vida é um entusiasmo perene. O Universo palpita e canta perpetuamente, numa jubilosa e ardente agitação que nunca se enfraquece. A mesma flama imorredoura anima a infinita variedade dos sêres e das coisas. Tudo é entusiasmo no kosmos." "E o verdadeiro patrio tísmo não é o amor dos negócios rendosos que no seio da pátria podem dar riqueza e a independência: não é a interessada gratidão pelas honrarias que dentro dela se podem granfear: não é também o embevecido êxtase, ingênuo e fútil, diante da beleza das suas paisagens, de explorador do seu ceu, da uberdade do seu solo. É sim, um amor elevado e austero, que reconhece os defeitos da pátria, não para amaldiçoá-los ou para rir dêles, mas para perdoá-los e corriq̣i-los: é um amor que se enraiza mais no seis mora ldo que no meio físico, e vai procurar a sua seiva nutritiva no âmago longinquo do passado, no sacrossanto humuns das origens da raça, da lingua, da história e no padecimento obscuro, apagado, anônimo das gerações que antes da nossa, viveram, suaram e penaram na terra que servimos e adoramos! Êste é o patriotismo com que deveis de ora em dista honrar a nossa terra."

E Bilac sempre aconselhou aos brasileiros a serem enérgicos, a terem confiança em si mesmos, a serem justos, modestos e tolerantes, mas nunca supondo que o esfôrço individual isolado, por si só, tudo realize, quando só o trabalho comum é forte e invensivel. Quando em consciência nos julgamos 
ao lado da boa causa e da justiça, defendamos com firmeza as nossas idéias, nunca, porém, hostilizando as opiniões alheias, "porque muitas vêzes um só minuto de tolerância e de cordura é mais eficaz do que todo um século de brutalidade e violência!" A cada passo trae-se no poeta o educador, estimulando a nossa energia, a nossa confiança e o nosso amor ao trabalho, fonte desta alegria de viver indispensável à criatura humana, para que ela seja feliz, ainda que envelheça ignorada e sem prêmio, ainda que assaltada pela ingratidão e pela calúnia, ainda que veja desconhecido o seu merecimento e incompreendido o seu labor. Para Bilac, a nossa verdadeira felicidade não está na recompensa do bem que fazemos, mas nesse próprio bem. "Só é verdadeiramente infeliz quem atravessa a vida como sombra inútil, sem deixar após si um trabalho de arte que delicie algumas almas, um progresso científico que melhore as condições da humanidade, uma tentativa em bem da paz e da ventura da espécie, ou, ao menos, um consôlo dado ao infortúnio geral, uma boa ação anônima e desinteressada, uma só palavra de amor e de piedade que mantenha o entusiasmo e a esperança dos seus semelhantes."

Por ser o espírito da criança extremamente sensível às sugestões do entusiasmo ou do desânimo, Bilac aconselhava que, principalmente nas escolas primárias, dado fôsse a inexperiência infantil a aquisição de sentimentos animadores, a fim de que as novas gerações se preparem para a vida bem apercebidas do que lhes facilite a vitória e não o fracasso, em seus empreendimentos. Dos ramos de ensino o que mais interessava a Bilac era a instrução primária, por ser ela a célula-mater da organização social. Por meio dêsse ramo de ensino, que se deve difundir ao máximo, evitar-se-á o definhamento e mesmo a morte da nacionalidade, porque a instrução primária conserva, expandindo-o, em todo o país o uso do idioma nacional, os versos dos seus poetas, a letra das suas canções populares, o texto de suas lendas e tradições: tudo quanto, afinal, sustenta e caracteriza o seu povo no espaço e no tempo.

Para o grave problema da difusão do ensino primário Bilac não se cansava de chamar a atenção dos nossos governantes e dos jovens aos quais os destinos do Brasil podessem vir a ser entregues um dia, alertando-os de que, mesmo quando o país todo se povoasse, cortado de estradas de comunicações fáceis e de meios rápidos de transportes e com tôdas as suas riquezas naturais conhecidas e exploradas, ainda assim o seu progresso não seria real, se a sua população não fôsse convenientemente instruida. Ao fazê-lo, Bilac estava apenas cumprindo um dever que a si mesmo se impusera para satisfação do seu amor ao Brasil, que êle imaginava fôsse a Terra da Promissão para "todos os homens sem trabalho e sem ventura, que se acogulam no âmbito já escasso do velko mundo" e que, apesar de vindos para um país estranho, podem encontrar aqui o de que precisam para viver em paz.

Nos breves minutos de que disponho para falar de Bilac educador, não poderei dizer tudo quanto deveria ser dito, como o fará quem se proponha a realização de um estudo menos apressado sôbre o mesmo tema. Em se tratando de assunto técnico, não é tarefa senão para os que tenham o trato das coisas educativas. Semeador de esperanças, visando ao bem-estar dos homens em sua rápida passagem pelo mundo mais de tristezas que alegrias, Bilac, calando as próprias decepçóes e amarguras, sempre se fêz arauto do quanto 
pudesse ao menos consolar os sofredores e servir de bálsamo às suas dores físicas e morais. No que dizia ou escrevia, êle jamais propagou o pessimismo, sinistro veículo de sutis venenos contra a felicidade humana. Para Bilac a esperança é o único bem real da vida, pois quem sabe esperar sempre alcança - que deseja. Mas, ao que já nos dizia Platão: "para alcançar qualquer coisa, é mister esperá-la com tôda a alma", e, segundo o nosso poeta, "de fato, a verdade, a felicidade, a fortuna, tôdas as riquezas materiais e morais que há na vida, não se oferecem voluntàriamente a quem as não procura: é preciso ir ao seu encontro ansiosamente e confiadamente, esperando-as."

Bilac também não desprezava o espiritual, a fim de que a educação do ser humano não se apresentasse mutilada, voltada apenas para as coisas terrenas e, portanto, materiais, preparadoras de criaturas estranhas ao seu próprio Criador, alheias às coisas divinas, porque descrentes. Entre as sug̣estivas páginas das suas Poesias Infantis encontra-se esta, que aliás não é a única de sentido religioso:

\section{AVE, MARIA!}

Meu filho! termina o dia;

A primeira estrêla brilha;

Procura tua cartilha,

E reza a Ave-Maria.

O gado volta aos currais;

O sino canta na igreja;

Pede a Deus que, generoso,

Te faça justo e bondoso,

Filho bom e homem honrado;

Que teus pais conserve aqui,

Para que possas, um dia,

Pagar-lhes em alegria

$\mathrm{O}$ que sofreram por ti.

Reza è procura o teu leito,

Para adormecer contente;

Dormirás tranquiilamente,

Se disseres satisfeito:

«Hoje pratiquei o bem;

Não tive um dia vazio,

Trabalhei, não fui vadio,

$\mathrm{E}$ não fiz mal a ninguém.»

O professor Alceu de Amoroso Lima, grande autoridade em assuntos culturais, diz, em o breve mas expressivo prefácio da antologia Olavo Bilac, organizada para uma das nossas casas editôras. " $\mathrm{O}$ poeta que nascera entre tambores e lágrimas, que vivera entre sêdas e carícias, ia encerrar a sua bela vida em campanhas pela instrução e pela defesa nacional, entre cartilhas e canhões, pregando um duplo evangelho de educação intelectual e de disciplina." E, a par de outras considerações judiciosas: "êsse homem nos legou, sem dúvida, a mais bela lição de amor à beleza e de culto ao Dever, conjugados em sua obra e em sua vida." 
Bilac, no entanto, teve de pagar o seu tributo à inveja, à maldade e à maledicência; ainda hoje há quem insista em atribuir-lhe defeitos que nêle jamais existiram, na realidade. A sua fama de boêmio no mau sentido não corresponde à verdade, mas, mesmo assim, se propagara e a muito custo vem-se desfazendo. Bilac era amigo de boêmios e, sendo solteirão, demorava-se, às vêzes, entre êles, a falar, quase sempre, de assuntos literários e artísticos. Isto, porém, bastou para que se lhe aplicasse o provérbio dize-me com quem andas, que eu te direi quem és. E Bilac passou a ser tido como bêbedo, desordenado e até de costumes pervertidos. $O$ poeta, no entanto, era um homen de vida organizada, o oposto da fama tão injustamente adquirida, não obstante a cada vêz maior admiração em que o tinham os leitores, à fôrça de ser Bilac no verso e na prosa o gênio da plasticidade, integralmente nosso, e impondo-se aos nossos ouvidos, à nossa memória, ao nosso coração, ao nosso espirito, como o disse o insuspeito Jackson de Figueiredo.

Tendo nascido em 1865 e vivido a sua primeira infância em uma atmosfera heróica, resultante da nossa ação bélica nos campos do Paraguai, Bilac impregnou-se de reminiscências daquela fase de euforia patriótica, que enchera e maravilhara tôda a sua adolescência. E é ainda o professor Alceu de Amoroso Lima quem o diz: "Essa mesma atmosfera marcial, de entusiasmo e exaltação guerreira, é que iria cercar o crepúsculo prematuro de sua vida, com pouco mais de cinqüenta anos de idade, quando se lançou na campanha do serviço militar obrigatório e da defesa nacional, estimulada certamente pelo clima da primeira grande guerra mundial, e de entusiasmo despertado, no Brasil e em geral por tôda a América, pela causa dos aliados, como entâo se dizia, e particularmente da França, que sempre foi, junto a Portugal, uma das grandes paixões do Poeta. Nasceu e morreu, por conseguinte, como um Píndaro sul-americano, unindo a Poesia e o Civismo, aula de lirismo bélico, que a segunda guerra mundial e a era atômica iriam encarregar-se de eliminar das gerações que lhe sucederam."

Sem se dizer pedagogo, o poeta, no entanto, firmava-se no que de mais moderno havia na pedagogia do seu tempo, ou melhor, do nosso tempo. Por isto mesmo, no tocante à formação cívica da juventude patrícia, Bilac pôde sòzinho despertar, valendo-se tão só do fascínio convicente da sua palavra, a alma nacional. Graças à sua pregação patriótica, ruiram por terra, desde logo, todos os preconceitos contra o militarismo em nosso país.

$\mathrm{E}$ isto representa de fato obra de verdadeiro educador, sempre empenhado em que as novas gerações compatricias tivesse uma formação física, moral, espiritual e técnica de maneira a satisfazer as exigências do mundo atual, que já se vinha varrendo por um sôpro de tragédia, como se Deus houvesse transferido aos homens o encargo da própria destruição, poupando-se ao processamento do Juizo Final, antes de cuja hora suprema, como o disse Jesus, anunciando-o há quase dois milênios: "levantar-se-á nação contra nação, e reino contra reino, e haverá fomes, e pestes, e terremotos, em vários lugares." $\mathrm{E}$, depois de tanta desgraça e de tanta aflição, "o sol escurecerá o seu resplendor, e as estrêlas cairão do céu, e as potências dos céus serão abaladas." 
Bilac, todavia, "tendo sido um homem que amou a vida apaixonadamente, nunca soube perceber para lá dos horizontes terrenos, os verdadeiros horizontes da Vida que não morre." Espírito cristão, porém voltado para as coisas dêste mundo, se, algumas vêzes, pensou na Vida eterna, jamais procurou aprofundar-se nos mistérios do Além. Manifesta sempre foi, como pensador, a sua incapacidade para o transcedente. $O$ artista, quando se voltava para os assuntos metafísicos, transformava-os em simples motivos literários. Mas, para o educador, a Religião era uma necessidade imperiosa, absolutamente indispensável à boa formação da personalidade humana.

Examinando-se-lhe a obra educacional, a muitos há de parecer curioso como o poeta, que punha nas coisas o sabor voluptuoso dos frutos proibidos, de tal maneira se transfigurasse em um educador sisudo, pregando à juventude o seu evangelho misto de educação moral e civica, tudo de acôrdo com os métodos e processos mais modernos. Para Bilac, todos os homens deveriam estar convenientemente preparados para a luta de todos os tempos entre o Bem e o Mal, luta essa que, na segunda metade do século XX, mais se agravaria, núncia de hecatombe universal, o que, no entanto, não se previra pelo poeta, tanto o seu otimismo semeador de esperanças benfazejas.

Em 1907, recebendo a maior consagração já prestada no Brasil a um poeta, pois the foi oferecido um grande banquete, no qual estavam representadas tôdas as classes sociais, Bilac teve oportunidade de proferir importante discurso, assinalando uma nova fase para a vida cultural brasileira: "O que estais, como Brasileiros, louvando e premiando, nesta sala, é o trabalho árduo, fecundo, revolucionário, corajoso, da geração literária a que pertenço... Há quarenta anos que não havia pròpriamente homens de letras no Brasil: havia estadistas, parlamentares, professôres, diplomatas, homens de sociedade ou homens ricos, que, de quando em quando, invadiam por momentos o bairro literário...» - «Que fizemos nós? Fizemos isto: transformamos o que era então um passatempo, um divertimento, naquilo que é hoje uma profissão, um culto, um sacerdócio. Tomamos o lugar que nos era devido no seio da sociedade. Podemos dizer que representamos, para o progresso intelectual do Brasil, na última metade do século XIX, o mesmo papel que, para o seu progresso material, representaram, no século XVII, os heróis das bandeiras... Abrimos, desmoronamos, pulverizamos a pretenciosa tôrre de orgulho e de sonho em que o artista queria conservar-se fechado e superior aos outros homens, viemos trabalhar cá em baixo, no seio do formigueiro humano, ansiando com os outros homens, sofrendo com êles, padecendo com êles tôdas as desilusões e todos os desenganos da vida... Não nos limitamos a adorar e a cultivar a Arte pura, não houve problema social que não nos preocupasse e, sendo homens de letras, não deixamos de ser homens."

Bilac foi, graças ao seu próprio mérito entre os homens um Homem, cujos atos e palavras o tornaram um apóstolo do Bem, visando à felicidade humana. Pena é que o poeta tenha morrido em plena maturidade, quando o Brasil mais esperava da sua capacidade e do seu patriotismo. Contudo êle muito já havia dado de si, tornando-se credor do nosso reconhecimento e da nossa admiração. A sua memória jamais deixará de ser objeto de perma- 
nente e intenso culto, pois não é dessas que fàcilmente se relegam ao esquecimento. A sua vida e a sua obra serão, através dos tempos, a mais bela lição de esperanças no Futuro, tendo em mira a grandeza da Pátria, em um mundo melhor, no qual todos os homens possam viver felizes.

Se o Brasil contasse permanentemente com alguns brasileiros do valor de Olavo Bilac, tudo lhe seria ascenção gloriosa, tornando menos afastado êsse porvir de belas conquistas, que todos tantos aspiramos para a nacionalidade. O poeta sempre pugnou por um Brasil de acôrdo com as suas próprias possibilidades humanas e materiais, e fê-lo indiferente a recompensas, além da cie bem servir à pátria. Cumpriu dignamente a sua missão de artista e de cidadão, realizando uma obra de cultura e de beleza, ao mesmo tempo que impondo-se como exemplo de verdadeiro patriota, impregnado dêsse nacionalismo que não compromete a paz, o progresso e a prosperidade nacionais.

Bilac foi, sem dúvida, um dos belos espécimes da nossa civilização. Nêle encontramos um exemplar humano dos mais bem dotados e portanto, dos que se têm aos que muito nos deram de si, desejando a nossa crescente prosperidade. Tanto pela inteligência quanto pela bondade, Olavo Bilac dignificou a espécie e há sempre relembrar-se à maneira de um nome tutelar. 